\title{
Strain Rate Effects on Mode I Fracture of Unidirectional Carbon Fiber Composites
}

\author{
Amit G. Salvi* and Anthony M. Waas \\ Composite Structures Laboratory, \\ Department of Aerospace Engineering, \\ University of Michigan, Ann Arbor, MI, 48109-2140 \\ Ari Caliskan \\ Ford Motor Company, Safety R and D Dept., \\ 20000 Rotunda Dr, Dearborn, MI 48121
}

\begin{abstract}
Unidirectional carbon fiber composites were subjected to the Iosipescu shear test under static and low velocity impact conditions (LVI). Specimens were cut for $0^{0}$ and $90^{0}$ test configurations. Static tests were carried out on a hydraulically activated MTS loading frame, where specimens were subjected to uniform straining. LVI tests were conducted on a drop tower facility. The shear response of the specimen was measured for both $0^{0}$ and $90^{\circ}$ specimen configurations.

Strain rate effects on interfacial crack toughness were also measured. Pre-notched unidirectional stitched carbon fiber specimens were subjected to a static and LVI three point bend test. The crack propagation velocity was measured with the help of special crack propagation gages and a high resolution digital camera. Load vs. load point displacement was measured for every test. The effect of strain rate on fracture toughness was characterized.
\end{abstract}

\section{Introduction}

The ultimate strength and toughness of a composite material are indication of its ability to absorb energy when subjected to crush loads, either applied slowly or within a short duration. Because braided and fabric composite structures contain a well-defined microstructure, both the ultimate strength and toughness can be related to micro structural variables. In turn, these microstructural features and their behav-

\footnotetext{
* Graduate Student Research Assistant.

${ }^{\dagger}$ Professor of Aerospace Engineering, Associate Fellow AIAA.

$\ddagger$ Research Engineer

${ }^{0}$ Copyright (C) 2002 by Anthony M. Waas. Published by the American Institute of Aeronautics and Astronautics, Inc. by permission.
}

ior are reflected at the macro level. For example, the rate sensitivity of the matrix and the rate sensitivity of the fiber/matrix interface can contribute to the overall rate sensitivity of a composite material at the macroscopic level.

Previous work ${ }^{1}$ (Salvi and Waas, 2002) using glass fiber reinforced braided textile composite tubes have revealed the following important observations with respect to energy absorption. Tests were carried out on $[0 / \pm 30]$ braided fabric square crosssection tubes at static and impact velocities in the range of 3 to $10 \mathrm{~m} / \mathrm{sec}$. For this range of impact velocity, it was observed that the crush velocity remains fairly constant during the crush process ${ }^{2}$. The constant velocity was achieved using a high kinetic energy of impact. Under these conditions, it has been observed that the tubes fail by delamination as the most dominant mode of failure with substantial fiber/matrix separation occurring in the delaminated fronds. It has also been observed that the crushed tubes always show a larger amount of delamination compared with statically crushed tubes. The resin used for the tubes is slightly rate sensitive, however, this indicates that the resin is stiffer and stronger under dynamic conditions. Yet, the dynamically crushed tubes consistently absorb less energy than the statically crushed tubes, always at a lower mean "plateau" load. Motivated by these findings, the present work is aimed at understanding the shear response of unidirectional stitched composite plates and the mode I fracture toughness of such plates for crack propagation in the fiber tow direc-

\footnotetext{
${ }^{1}$ Automotive composite consortium, Energy Management Work Group.

${ }^{2}$ This is an assumption. In general, strain gages placed on the specimen surface during the test shows that strain rate is not constant but changes throughout the loading process.
} 
tion. The present investigation of crack growth is limited to static and LVI loading conditions. Under LVI conditions, the dynamic stress field produced by the impact loading subsides and this transient field occurs at the very early stages of loading. In the present experiments, the maximum impactor velocity is $4.6 \mathrm{~m} / \mathrm{sec}$, resulting in maximum crack velocities on the order of $350 \mathrm{~m} / \mathrm{sec}$. These velocities are a small fraction of the shear wave speed (1540 $\mathrm{m} / \mathrm{sec}$ ) and Rayleigh wave speed of the material. Consequently, dynamic effects can be neglected. It is to be noted that Rosakis et al. (1997), Lambros and Rosakis (1997), Liu et al. (1998a) and Coker and Rosakis (2001) have conducted an extensive experimental and numerical investigation of dynamic crack propagation in unidirectional continuous fiber (prepreg) laminated composites, whereas the present study examines continuous fiber (textile tows) unidirectional composites.

\section{Material Description}

Unidirectional stitched carbon fiber textile composites were used for this study. Fibers are stitched together in bundles to form fiber tows. Approximately 80,000 fibers are bundled in one tow. These fiber tows are then stitched together to form a fiber mat. Ten such fiber mats are stacked one on top of another and vinyl ester resin is infused. This gives the resulting material a unique microstructure as shown in figure 1 .

\section{Iosipescu Shear Test}

\subsection{Specimen Geometry}

The dimensions of the test specimens are described in figure 2(a). The test specimens are cut at $0^{0}$ and $90^{\circ}$ with respect to the direction of loading. This configuration gives both a direct and an indirect measure of shear load transfer between fiber tows and matrix.

\subsection{Experimental Procedure}

Static Iosipescu shear tests (Ref.6) were carried out by using an Iosipescu shear fixture as shown in figure $2(\mathrm{~b})$. The loading frame cross-head motion of $0.00508 \mathrm{~mm} / \mathrm{sec}$ is applied to the moving grip of the Iosipescu shear fixture. Load is measured by a load cell mounted on the actuator of the MTS load- ing frame. A three strain gage rosette is placed in the notch area to measure the strain state in the specimen.

Quasi-static impact Iosipescu shear tests are carried out with an actuator velocity of 50.80 $\mathrm{mm} / \mathrm{sec}$. LVI tests are carried out on a drop tower. A dead weight of approximately 43kgs. is dropped on the moving grip of the Iosipescu shear fixture. Load is measured via a load cell placed in the impactor of the drop tower.

\subsection{Shear Stress vs. Shear Strain Be- havior Under Static and Low Ve- locity Impact Conditions}

Figure 3(a) shows the shear response of the $0^{0}$ specimen configuration. Figure $3(\mathrm{~b})$ shows the shear response of the $90^{\circ}$ specimen configuration. The values of shear modulus $G_{12}$ are shown in table 1.

\section{$4 \quad$ Three Point Bend (Fracture) Tests}

\subsection{Specimen Geometry}

The dimensions of the test specimens are described in Figure 4(a). The test specimens of size $63.50 \mathrm{~mm} \times 88.90 \mathrm{~mm}$ (2.5inch by 3.5 inch) are cut such that the fiber tows lie in the direction of the loading. A centrally placed end notch $1 \mathrm{~mm}$ wide and $12.70 \mathrm{~mm}$ in depth is introduced. A sharp knife edge is used to make the crack tip fine.

\subsection{Experimental Procedure}

Specimens are loaded in a three point bend configuration with the help of three steel rollers of dia. $12.70 \mathrm{~mm}(0.50 \mathrm{inch})$. The top roller is placed along the line of the crack. Bottom rollers are placed $76.2 \mathrm{~mm}$ apart and the specimen is centered on these rollers.

\subsubsection{Static Fracture Test}

Static Fracture tests are carried out on a hydraulically activated MTS loading machine. Load is introduced through the top loading pin at the rate 
of $0.01016 \mathrm{~mm} / \mathrm{sec}$. Load and load point displacement are recorded. Simultaneously a high resolution Kodak digital camera (2028 x 2044 pixels) is programmed to capture pictures of the propagating crack at every 1 second intervals. Thus the extension of the crack is measured at every second during the loading of the specimen. The loading is terminated when the crack reaches the top roller.

\subsubsection{Low Velocity Impact Fracture Test}

LVI tests are carried out on a drop tower facility. The test configuration is similar to the static tests. A drop weight of approximately $43 \mathrm{Kgs}$. is dropped on the top loading pin from heights of $40 \mathrm{~cm}$ (impactor velocity: $2.8 \mathrm{~m} / \mathrm{sec}$ ) and $108 \mathrm{~cm}$ (impactor velocity: $4.6 \mathrm{~m} / \mathrm{sec}$ ). Load experienced by the specimen is measured by a Kistler impact load cell which is attached to the impactor. The force signal is then used to calculate the acceleration of the top loading pin (by dividing the force signal by the mass of the impactor). This acceleration is integrated once to get the velocity of the loading pin and twice to get the position of the loading pin. It is found that the deflection of the loading pin is uniform which implies that sufficient energy is provided by the impactor to maintain a constant displacement rate of loading. The recorded load and load point displacement are plotted against each other for all the LVI tests.

A special crack propagation gage, connected across a simple electrical circuit, is used to detect the crack position during the LVI test. The gage consists of a pattern of parallel lines made of conducting material and placed at known distances. This gage is placed in the path of the crack. As the crack progresses it cuts these lines in its path thus altering the electrical resistance across it. A high speed data acquisition oscilloscope $(2 \mathrm{GHz})$ is used to detect the change in the resistance across the crack propagation gage. A calibration curve of distance vs. the resistance is used to calculate the position of the crack as a function of time.

A high speed digital camera (capable of taking pictures at every 100 nanosec) is also used to capture images of crack propagation during loading. This camera is triggered as soon as the impactor hits the specimen and 8 subsequent pictures are taken at pre-specified time intervals. The images are analyzed to cross check the data obtained from the crack propagation gage.

\subsection{Experimental Observations}

\subsubsection{Static Fracture Tests}

Load vs. load point displacement data are shown in figure 5(a). The point at which the initial crack starts to grow is also indicated. When the load point displacement $\delta$ reaches approximately $1.20 \mathrm{~mm}$, the crack has reached the vicinity of the load point roller. Thus, beyond this $\delta$, the data is a measure of the crack propagation into material that has been crushed by the load point roller. We shall not consider the data beyond $\delta=1.20 \mathrm{~mm}$ any further.

Figure 5(b) shows the photographed area of the notch during crack propagation. While the primary crack is growing, secondary crack formation as shown in figure 5(b) was noted. Post experiment micrograph from regions adjacent to the primary crack indicated substantial secondary cracking due to static loading. This is discussed in detail in later sections.

It is clear that the primary crack propagation is not smooth indicating durations of no crack growth and spurts of crack growth occurring almost instantaneously. On average, we can identify two regions of almost constant velocity crack growth as shown in figure $5(\mathrm{c})$.

\subsubsection{Low Velocity Impact Fracture Tests}

Figure 6(a) shows the measurement of the load point displacement under static and LVI conditions. Figure 6(b) shows a typical signal from the special crack propagation gage for LVI tests. This crack propagation gage provides an accurate and consistent measure of the crack location during LVI tests. Figure 6(c) shows a typical load vs. load point displacement behavior for a LVI tests carried out at an impactor velocity of $2.8 \mathrm{~m} / \mathrm{sec}$. LVI tests were observed to be very sensitive to the notch position along the microstructure of the specimen (whether the initial notch is placed between two tows or through a single fiber tow).

Pictures taken with the help of the high speed camera are shown in figure $6(\mathrm{~d})$. The position of the crack visually measured from these images is found to be consistent with the readings obtained from the crack propagation gage. 


\subsection{Energy Absorption Under Static and Low Velocity Impact Condi- tions}

Figure 7 shows the comparison between the load vs. the load point behavior for static and LVI tests. The maximum load for the LVI tests are observed to be consistently lower than that of the static test. The area under the curve is approximately a measure of the energy absorbed during the loading duration. Consequently, it is seen that in these specimens, under mode I fracture conditions, the energy absorption is greater for static fracture when compared against the LVI cases.

Higher static load (and fracture energy) can be attributed to rate dependant inelastic mechanisms that are at work during crack propagation. Under static conditions, the specimen is observed to have a considerable amount of fiber bridging associated with primary crack propagation (even though the specimen is unidirectional). In addition, secondary cracking is also visible. This implies that the crack interface is "fuzzy". Even though a crack has propagated in the material, it is not failed completely. Under LVI conditions, the crack interface is much smoother compared to the static case. Fiber bridging is observed to be very small or almost absent. This results in the rapid drop of load accompanying crack growth.

The measurements indicate that LVI crack growth initiates at a time duration much shorter than the static case. Consequently, the strain energy stored in the specimen prior to crack growth is much smaller for the LVI case compared to the static case. In addition, this strain energy is more focussed and localized around the crack tip region. Sections 4.5.1 and 4.5.2 provide additional evidence to substantiate these claims.

The size of the damage zone in front of the notch during static crack initiation and growth is found to be much larger than that corresponding to the LVI case. The trend in the data shows that the size of the damage zone associated with crack propagation decreases as the crack velocity (or the rate of loading) increases. This is further discussed in section 4.5.3.

\subsection{Discussion}

\subsubsection{Crack Initiation Point}

For the fracture tests (static as well as LVI), the load reading at the point of crack initiation is noted, i.e. the load at which the first crack growth appears.

Table 2 lists the load and load point displacement corresponding to crack initiation. For static tests, the crack initiates after a sufficiently long time after initiation of loading. Due to the longer time period, the entire specimen is allowed to deform before crack initiates i.e. strain energy is more diffused. Under LVI conditions, due to the very short time interval between load initiation and crack growth initiation, the specimen is unable to "redistribute" the load. Consequently, the deformation zone is localized. A smaller volume of material around the crack tip is subjected to intense stress and strain rate. To further strengthen this observation, strain gages were placed away from the intended crack path. The value of strain recorded by this gage was noted under static and LVI conditions. A typical strain vs. time curve is shown in figure 8(a). The maximum compressive strain in the specimen under static and LVI conditions as indicated by this gage are given in table 3 .

Under LVI conditions, because deformation energy is highly localized, a critical condition corresponding to a lower external load and external displacement is reached sooner. Thus, crack initiation occurs at a lower external load. Whereas, under static conditions, the deformation energy is more diffused, leading to the triggering of other energy absorption mechanisms. e.g.- secondary cracks.

\subsubsection{Load Point Displacement}

When load point displacement $\delta$, for static and LVI tests are compared, it is seen that for a given load, $\delta$ is much larger in the LVI case than the static case. Further, $\delta$ scales with the rate of loading, being largest for the case corresponding to an impactor velocity of $4.6 \mathrm{~m} / \mathrm{sec}$. For the same external load state, the amount by which the crack has grown is largest for the case of impactor velocity $4.6 \mathrm{~m} / \mathrm{sec}$ and smallest for the static case. Consequently, the load point displacement is largest for the case corresponding to an impactor velocity of $4.6 \mathrm{~m} / \mathrm{sec}$.

\subsubsection{Crack Tip Strains}

A strain gage was placed very near the crack tip on the specimen perpendicular to the intended crack path and ahead of the crack tip. The center of the gage was located at a distance $2 \mathrm{~mm}$ ahead of the crack tip. A typical strain vs. time plot is shown in figure 8(b). Crack tip strain values corresponding 
to the crack initiation point (measured for each test) are shown in table 4.

The value of strain under LVI conditions is very high compared to the static case. This substantiates the highly intense local deformation under LVI loading.

\subsubsection{Crack Path Interface}

For static tests, extreme fiber bridging of the crack path is observed. Fibers are pulled out away from the actual crack path forming a large damage (or process) zone. Cracked specimens are observed under a scanning electron microscope to investigate the damage.

Figure 9(a) shows fiber bridging in the crack path for static tests. Figure $9(\mathrm{~b})$ shows a comparison between a static and a LVI test specimen after fracture. Specimens are sectioned as shown in the figure. When the crack interface is viewed, it is seen that the crack surface is much smoother under LVI conditions. Figure 9(c) shows a comparison between static and LVI damage zones. As is clearly indicated in these images, extensive fiber/matrix separations accompany the primary crack propagation in the static case, whereas, dynamic crack growth occurs with very little energy dissipation occurring elsewhere (other than the primary crack path).

\section{Computational Model}

A computational model was constructed using linear analysis. The initial slope of the load vs. load point displacement curve was matched by using an adjusted value of shear modulus $G_{12}$ obtained from the Iosipescu shear test. Such an adjustment of $G_{12}$ was favored over a very detailed model of localized deformation under the roller supports. By using the commercially available finite element (FE) software package Abaqus, a nonlinear geometric analysis of the three point bend configuration was conducted. Crack length was varied and the equilibrium load vs. load point displacement curve was generated. Results obtained from such analyses are shown in figure 10(a) (static) and figure 10(b) (LVI). On this plots the experimental load vs. load point displacement measurements are also indicated. The material properties used in the FE analysis are;

$$
\begin{aligned}
& \Longrightarrow \text { Static } \\
& E_{22}=8.274 G P a, \quad E_{11}=79.289 G P a, \\
& G_{12}=1.173 G P a, \quad \nu_{12}=0.24
\end{aligned}
$$

$\Longrightarrow$ Low velocity impact

$$
\begin{gathered}
E_{22}=15.779 G P a, \quad E_{11}=79.289 G P a, \\
G_{12}=1.548 G P a, \quad \nu_{12}=0.703
\end{gathered}
$$

For a given crack length, the FE analyses enables us to calculate the recoverable elastic energy stored in the specimen, while, the experimental measurements provide the total energy absorbed at that same state. The difference between these two energies supplies the unrecoverable energy or the fracture toughness associated with crack growth. The fracture toughness is plotted against crack length in figure 10(c) for the static case and for the LVI case corresponding to an impactor velocity of $2.8 \mathrm{~m} / \mathrm{sec}$. As the crack grows, more resistance is encountered due to fiber bridging, with the bridging resistance increasing with the crack length. This rate of increase of fiber bridging toughness is larger for the static case when compared to the LVI case. This shows that static fracture leads to a larger damage zone ahead of the propagating crack (diffused damage), while, LVI crack propagation leads to a localized damage zone with the size of the damage zone scaling inversely with crack velocity. This implies that in the limit of exceedingly large crack tip velocities all of the external work input is transmitted "smoothly" to the crack for the creation of a clean fracture surface. Of course, these comments are applicable to very sharp cracks and to the present textile composites specimens. Clearly, there exists a "competition" between the dynamic mode I crack initiation toughness (Liu et al., 1998 and within the context of the present discussion) and the mode I fracture toughness.

\section{Concluding Remarks}

The shear rate dependency of the material and the mode I fracture toughness of unidirectional stitched carbon fiber textile composites have been characterized via experiments. Both, the elastic shear modulus and the inelastic shear response show a rate dependency with "hardening" behavior. The mode I fracture toughness shows a reverse trend with the rate of loading. It is found that the fracture toughness decreases with an increase in the rate of loading. The reasons for these observations are explained by appealing to the composite microstructure and the observed failure mechanisms. 


\section{Acknowledgements}

The authors wish to thank the DOE program management team and the Board and staff of the Automotive Composites Consortium. This work was sponsored by the Automotive Composites Consortium and the U. S. Department of Energy, Office of Transportation Technologies, Office of Advance Automotive Technologies, Lightweight Materials Program under Cooperative Agreement number DE-FC05-OR22910.

\section{$\underline{\text { References }}$}

[1] Salvi, A. and Waas, A. M., 2002, Strain rate effects on unidirectional textile carbon fiber composites, Journal of Composite Materials, in preparation. Also, ACC-EMWG workshop proceedings, January 2002.

[2] Rosakis, A. J., Liu, C., Stout, M. G. and Coker, D., 1997, , GALCIT SM report, California Institute of Technology, Pasadena, California., 97-8.

[3] Lambros, J. and Rosakis, A. J., 1995a, Shear dominated transonic interfacial crack growth in a bimaterial - I Experimental observations. Journal of the Mechanics and Physics of solids, 43,169 .

[4] Liu, C., Rosakis, A. J., Ellis, R. W. and Stout, M. G., 1998, A study of the fracture behavior of unidirectional fiber reinforced composite using coherent gradient sensing (CGS) interferometry, International Journal of Fracture, 90, 355.

[5] Coker, D. and Rosakis, A., 2001, Experimental observations of intersonic crack growth in asymmetrically loaded undirectional composites plates, Philosophical Magazine A, 81, 571595.

[6] Standard test method for shear properties of composite materials by the v-notched beam method. Designation : D5379/D5379M-98.

[7] Liu, C., Knauss, W. G., Rosakis, A. J., 1998b, Loading rates and the dynamic initiation toughness in brittle solids, International Journal of Fracture, 90, 103-118.

\begin{tabular}{ccc}
\hline $\begin{array}{c}\text { Test } \\
\text { Impactor velocity }\end{array}$ & $\begin{array}{c}G_{12}(\text { Zero }) \\
(\text { GPa })\end{array}$ & $\begin{array}{c}G_{12}(\text { Ninety }) \\
(\text { GPa })\end{array}$ \\
\hline \hline Static & 2.89 & 4.30 \\
$50.8 \mathrm{~mm} / \mathrm{sec}$ & 3.19 & 4.97 \\
$2.8 \mathrm{~m} / \mathrm{sec}$ & 3.32 & 5.74 \\
\hline
\end{tabular}

Table 1: Shear modulus of specimen under static and low velocity impact conditions using Iosipescu shear method

\begin{tabular}{ccc}
\hline $\begin{array}{c}\text { Test } \\
\text { Impator Velocity }\end{array}$ & $\begin{array}{c}\text { Load } \\
(\text { Newton })\end{array}$ & $\begin{array}{c}\delta \\
(\mathrm{mm})\end{array}$ \\
\hline \hline Static & 2813.00 & 0.28 \\
$(0.01016 \mathrm{~mm} / \mathrm{sec})$ & 2608.52 & 0.34 \\
\hline $2.8 \mathrm{~m} / \mathrm{sec}$ & 591.30 & 0.19 \\
& 560.45 & 0.15 \\
\hline $4.6 \mathrm{~m} / \mathrm{sec}$ & 306.71 & 0.13 \\
& 302.46 & 0.16 \\
\hline
\end{tabular}

Table 2: Load and load point displacement corresponding to crack initiation

\begin{tabular}{cc}
\hline Test & $\begin{array}{c}\text { FarFieldStrains } \\
\text { (Microstrains) }\end{array}$ \\
\hline \hline Static $(0.01016 \mathrm{~mm} / \mathrm{sec})$ & 1200.00 \\
$2.8 \mathrm{~mm} / \mathrm{sec}$ & 432.00 \\
$4.6 \mathrm{~m} / \mathrm{sec}$ & 163.00 \\
\hline
\end{tabular}

Table 3: Strains measured away from the crack path

\begin{tabular}{cc}
\hline Test & $\begin{array}{c}\text { CrackTipStrains } \\
\text { (Microstrains) }\end{array}$ \\
\hline \hline Static $(0.01016 \mathrm{~mm} / \mathrm{sec})$ & 744.00 \\
$2.8 \mathrm{~m} / \mathrm{sec}$ & 4190.00 \\
$4.6 \mathrm{~m} / \mathrm{sec}$ & 118857.00 \\
\hline
\end{tabular}

Table 4: Strains measured at crack tip during crack initiation 


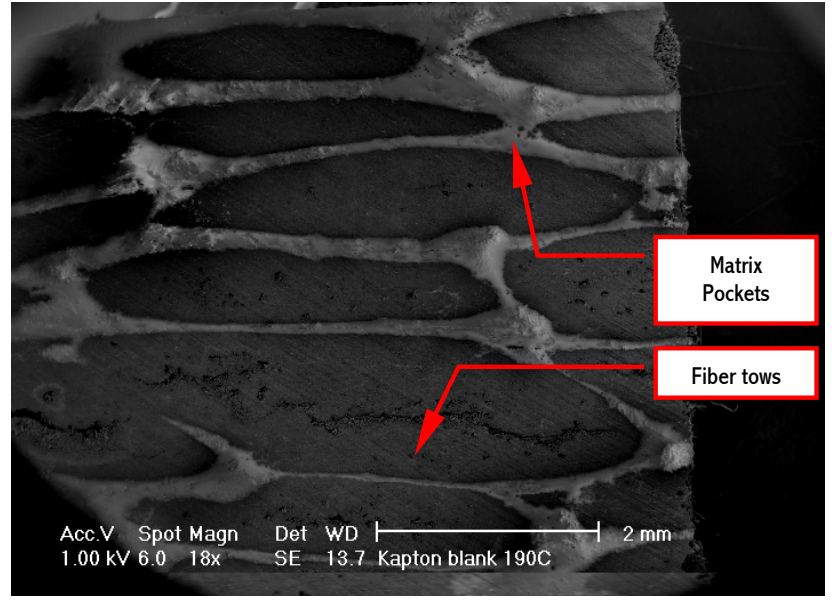

Figure 1.

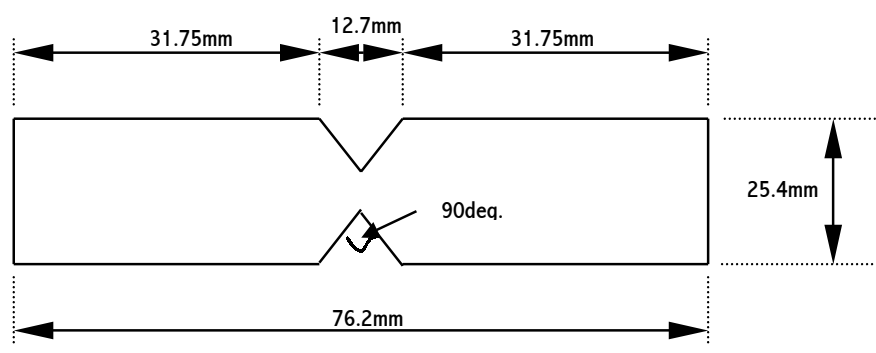

Figure 2(a).

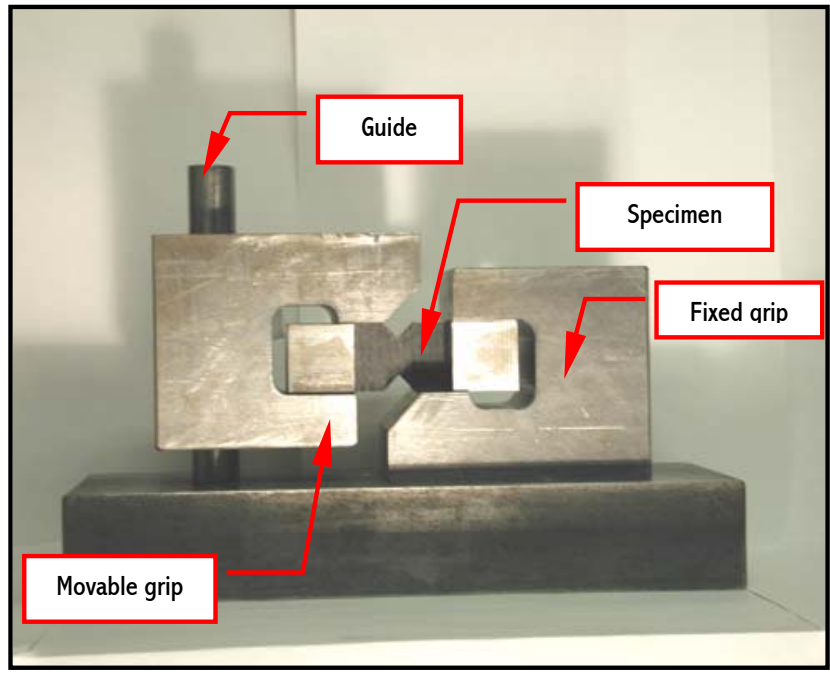

Figure 2(b).

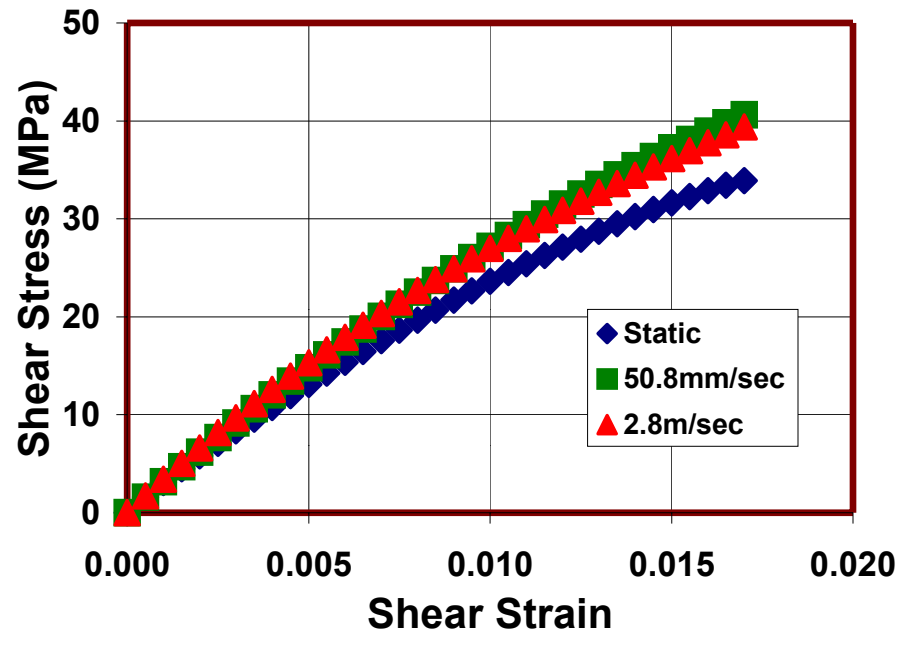

Figure 3(a).

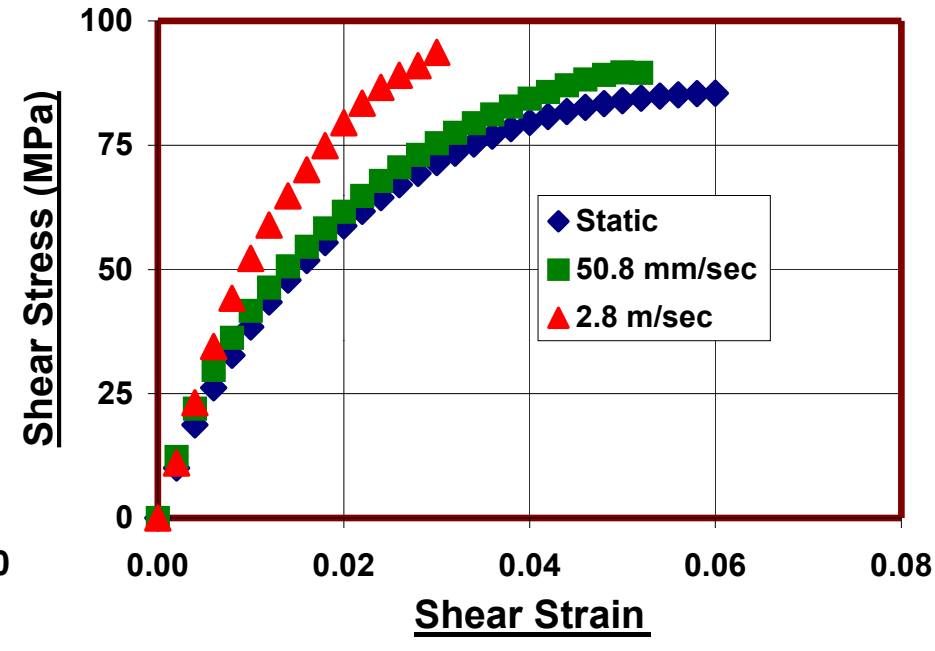

Figure 3(b). 
AIAA-2002-1614
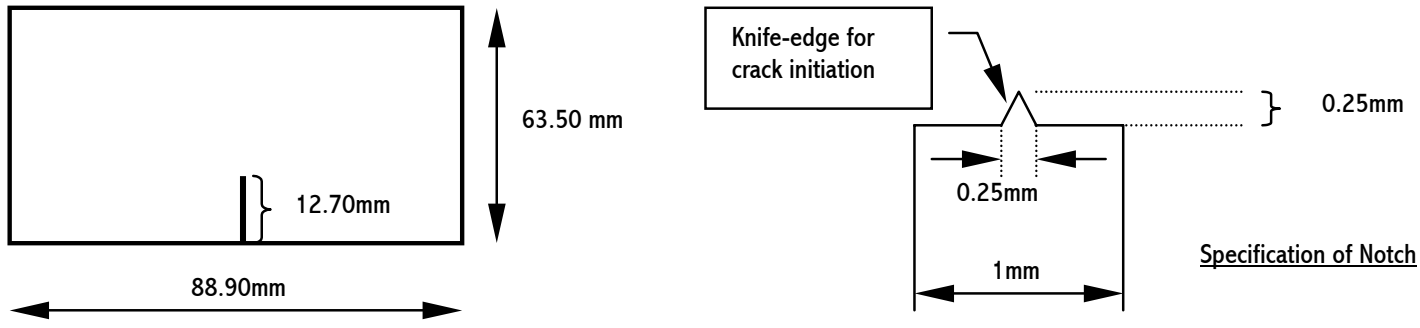

Figure 4(a).

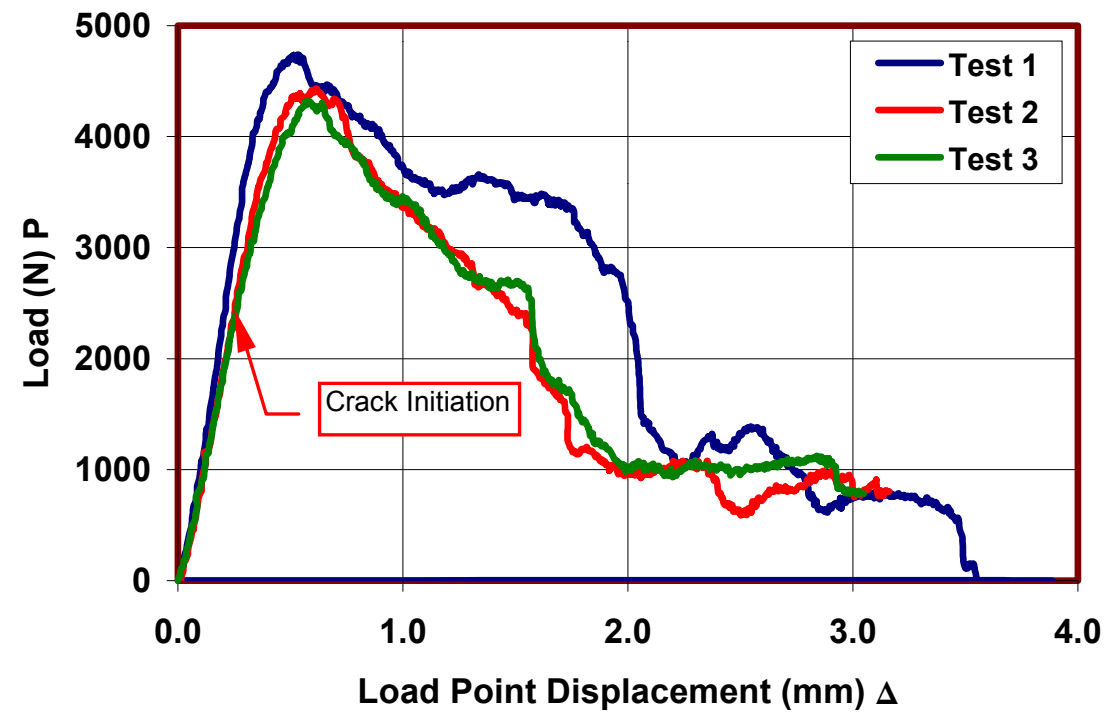

Figure 5(a).
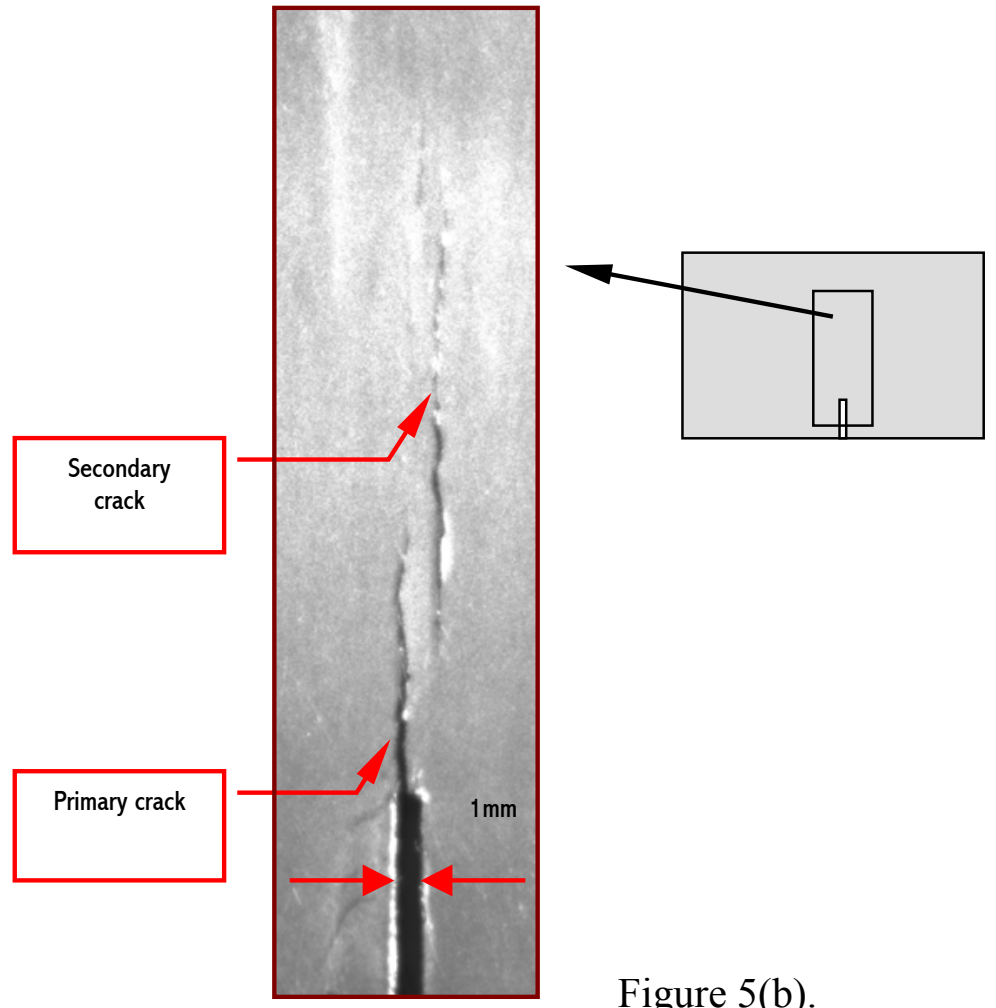

Figure 5(b). 


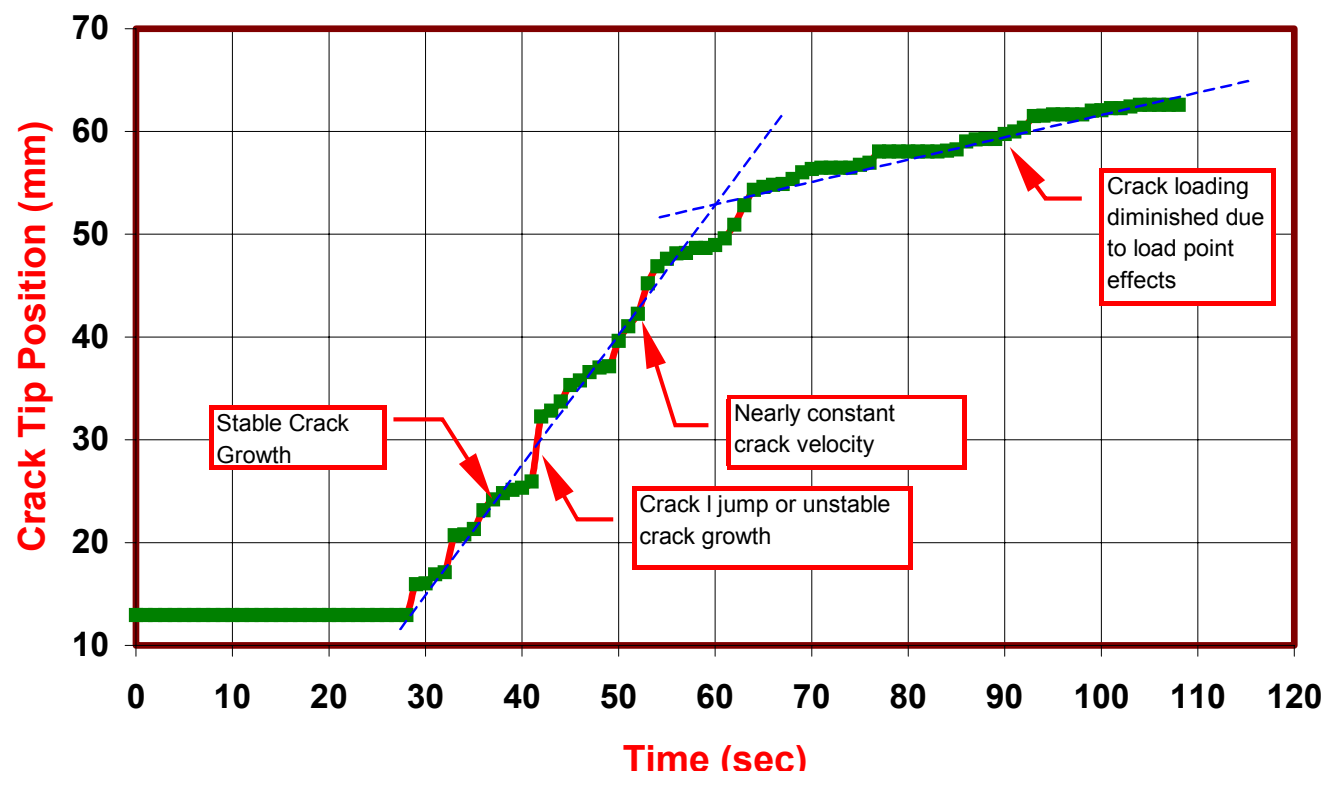

Figure 5(c).

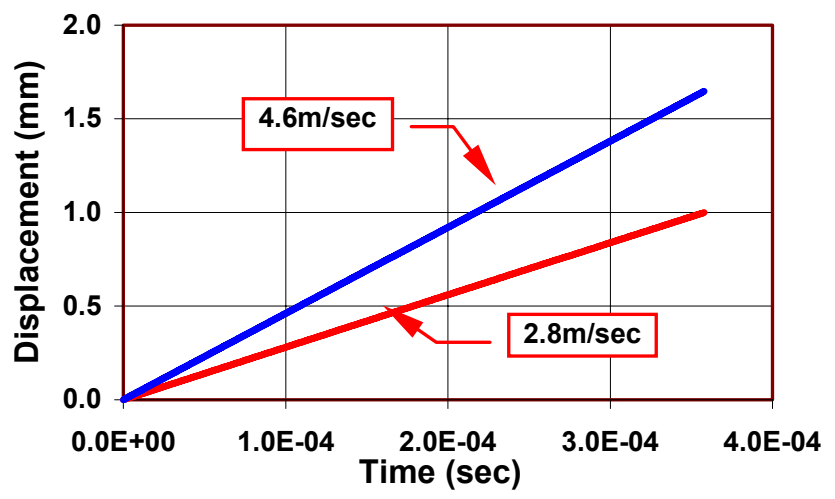

Figure 6(a).

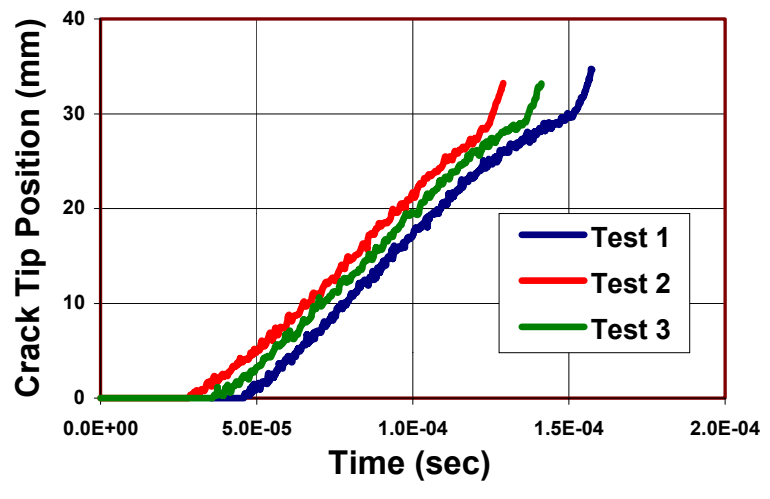

Figure 6(b).

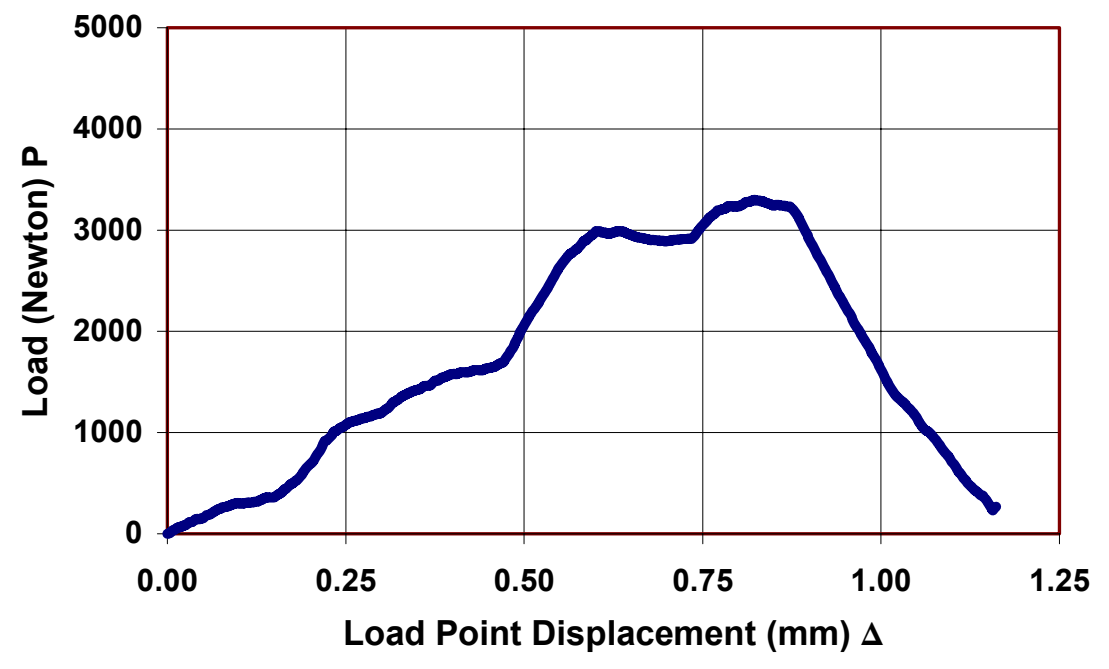

Figure 6(c). 


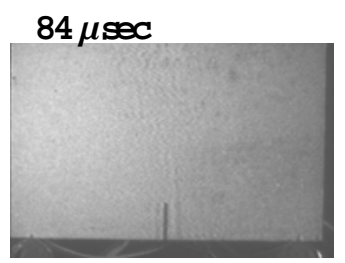

$124 \mu \mathrm{sec}$

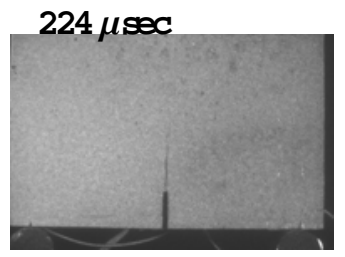

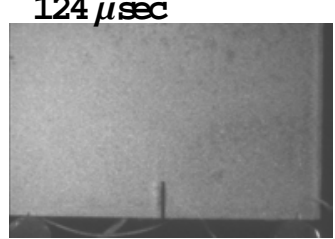

$239 \mu$ sec

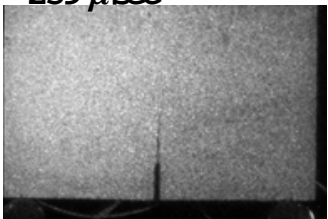

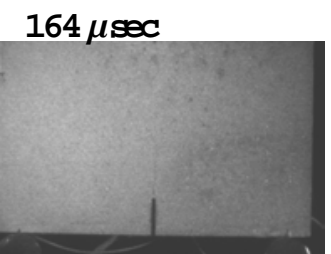

$244 \mu$ sec

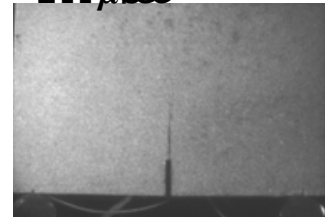

$204 \mu \mathrm{sec}$

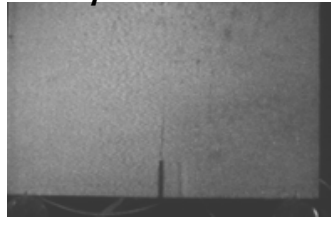

$269 \mu$ sec

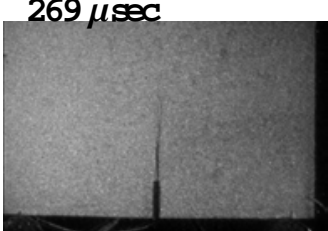

Figure 6(d).

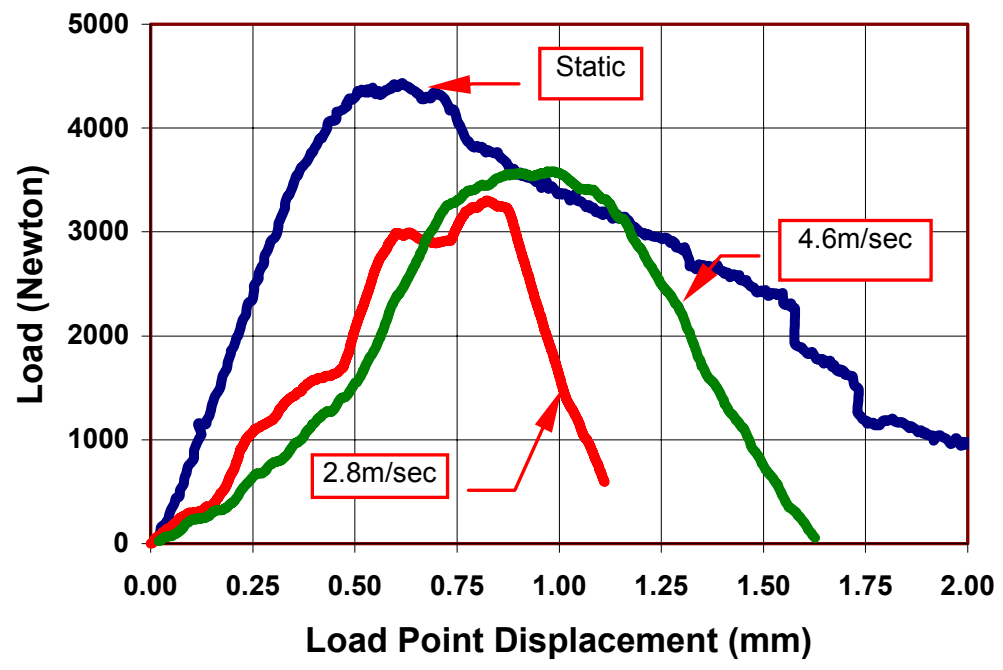

Figure 7.

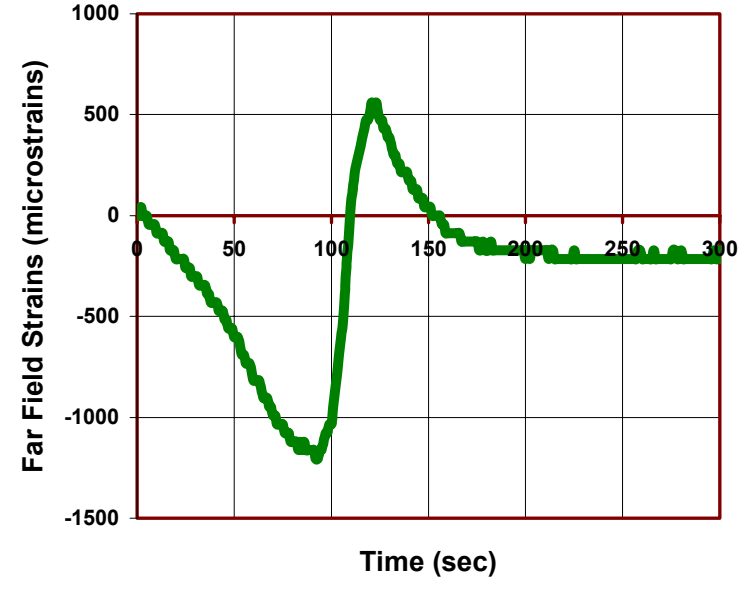

Figure 8(a).

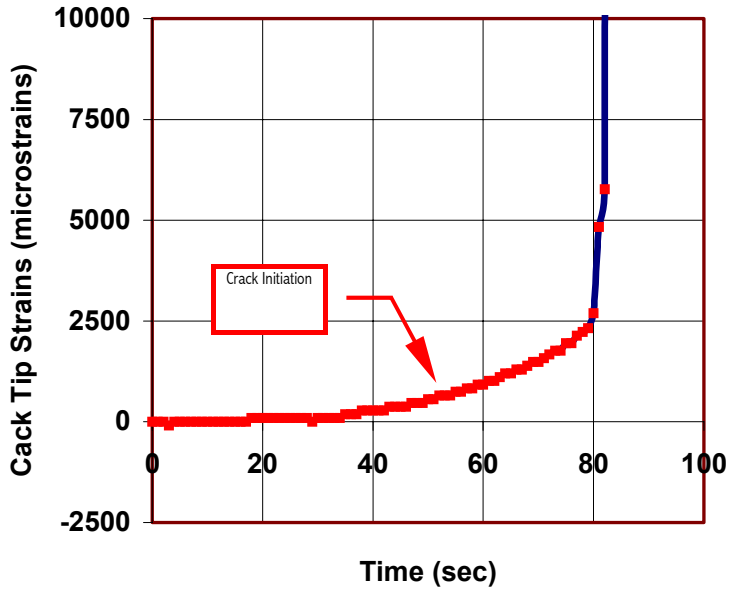

Figure 8(b). 

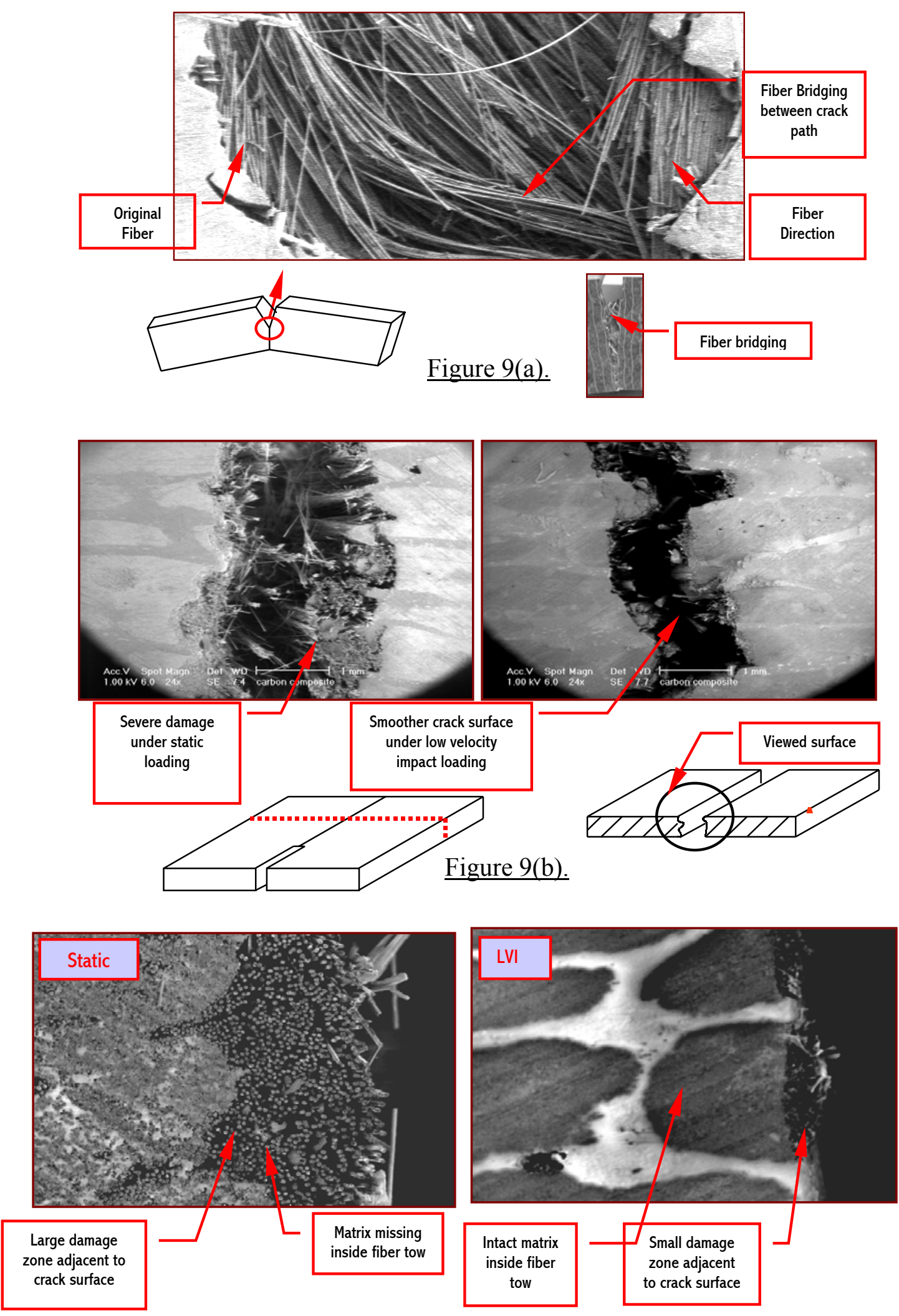

Figure 9(c). 
AIAA-2002-1614

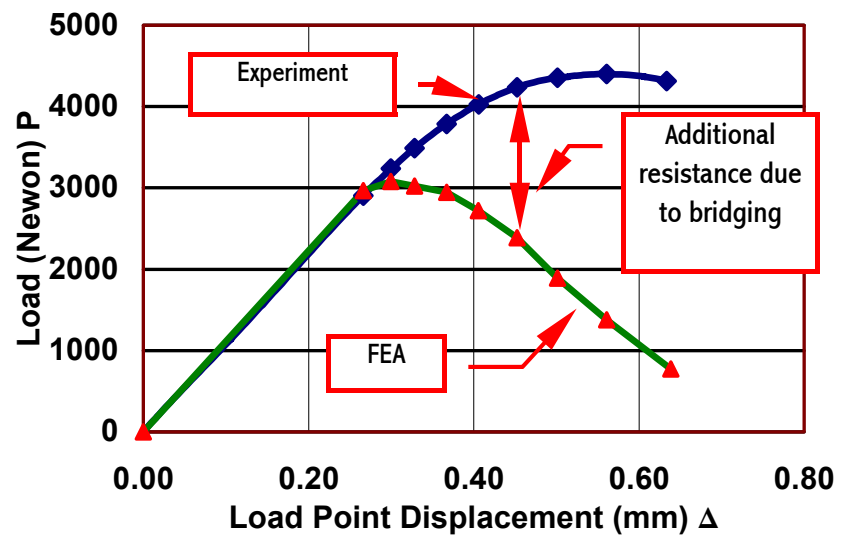

Figure 10(a).

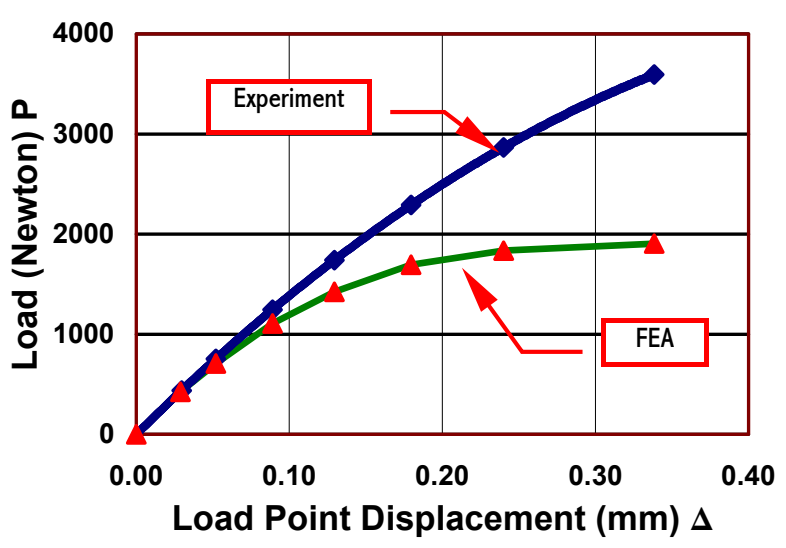

Figure 10(b).

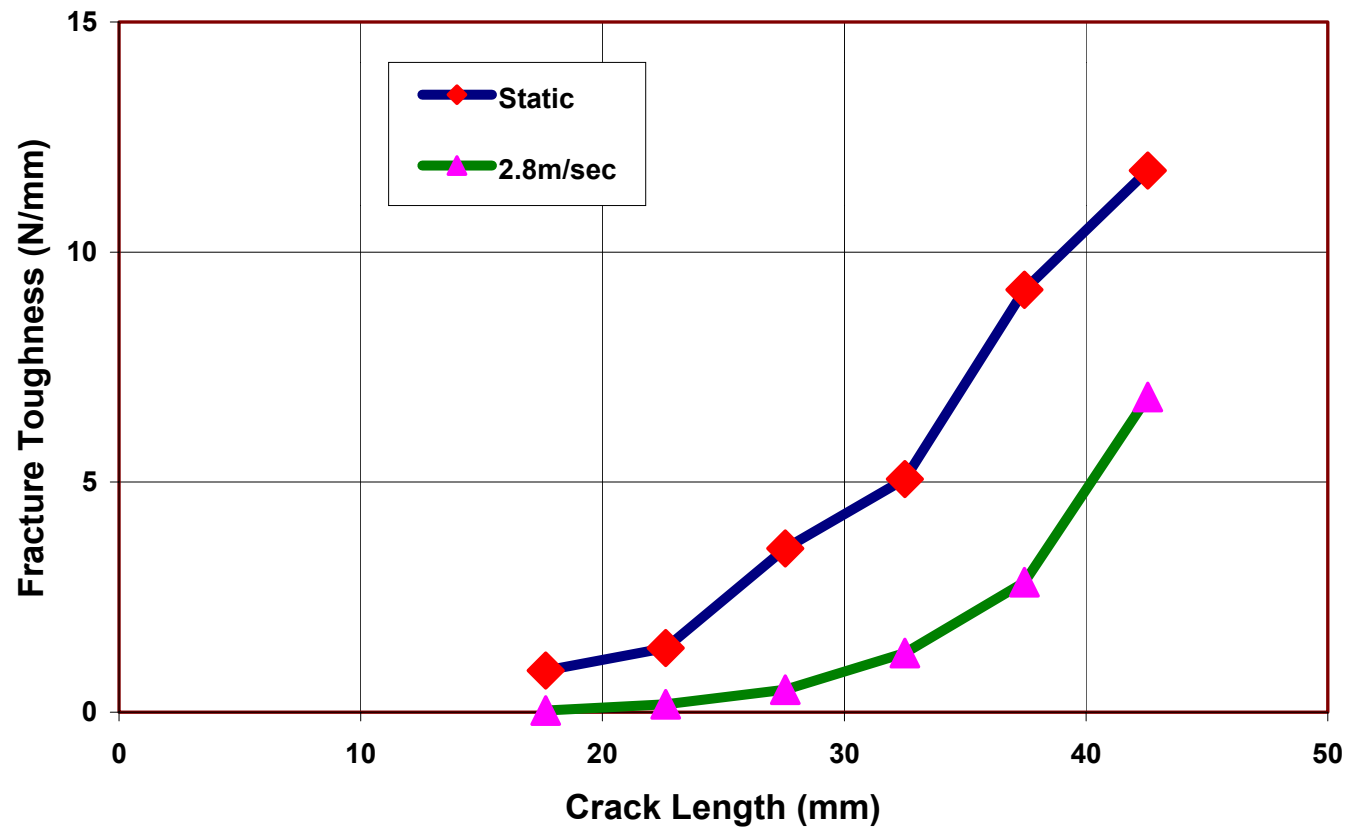

Figure 10(c). 